\title{
A construção de projetos pedagógicos na formação de profissionais da saúde
}

\author{
The conception of pedagogical projects in the education \\ of health professionals
}

\author{
Marta Quintanilha Gomes ${ }^{1}$ \\ 'Universidade Federal de Ciências da Saúde de Porto Alegre, Porto Alegre (RS), Brasil.
}

\begin{abstract}
RESUMO
Introdução: O texto apresenta excerto de pesquisa realizada a partir da análise dos projetos pedagógicos dos Cursos de Especialização em Saúde da Família, promovidos pela Rede UNA-SUS. O objetivo é investigar os projetos pedagógicos na área da saúde analisando como foram construídos tais documentos, tendo como referências as orientações pedagógicas inerentes à construção de um projeto pedagógico. Desenvo/vimento: O mote é compreender de que forma está sendo realizada a articulação das áreas da saúde e da educação na elaboração de projetos de curso. O trabalho de pesquisa ocorreu a partir da análise de oito projetos, acrescido de questionário respondido pelas coordenações pedagógicas. A abordagem metodológica é qualitativa utilizando pesquisa documental e entrevistas na coleta de dados. Este texto abordará as seguintes categorias: a organização dos projetos pedagógicos dos cursos; autorias e autores; e a coordenação pedagógica nos processos de formação. Considerações finais: Os resultados apontam para a coesão dos trabalhos em termos de justificativa e objetivos, no que tange à qualificação da formação dos profissionais para o trabalho no SUS. Indicam que há certa fragilização em alguns documentos em relação ao suporte teórico que baliza concepções de trabalho, mais especificamente na escolha metodológica e no processo de avaliação, ainda que os autores citados como parceiros teóricos pudessem apresentar apoio a tais concepções. Os projetos foram construídos por equipes, indicando um processo de elaboração colaborativa. Os cursos são coordenados, na grande maioria, por profissionais com aproximação à área da educação.
\end{abstract}

PALAVRAS-CHAVE: Projeto pedagógico. Formação profissional. Sistema Único de Saúde.

Recebido: Maio 30, 2016 Aceito: Set. 04, 2016

\section{COMO CITAR ESTE ARTIGO Gomes $M Q$. A construção de projetos pedagógicos na formação de pedagógicos na formação de profissionais da saúde. Interdisciplinary Journal of Health Education. 2016 Jan-Jul;1(1):13-22. http://dx.doi. org/10.4322/ijhe2016003. \\ CORRESPONDÊNCIA \\ Marta Quintanilha Gomes \\ Rua Ramiro Barcelos, 1660-1101, \\ CEP 90035-002, Rio Branco, Porto \\ Alegre (RS), Brasil \\ e-mail: martaqg@ufcspa.edu.br}

\section{FONTE DE FINANCIAMENTO} Nenhuma.

\section{CONFLITO DE INTERESSE}

Os autores declararam não

haver conflitos de interesse.

\section{O estudo foi realizado em} Porto Alegre (RS), Brasil.

Todos os autores leram e aprovam

a versão final submetida ao

Interdisciplinary Journal of

Health Education (IJHE).

\section{ABSTRACT}

Introduction: The text introduces a fragment of a research conducted from the analysis of pedagogical projects from post-graduate courses in Family Health sponsored by Rede UNA-SUS. The objective is to investigate the health educational projects analyzing how such documents were built, taking as reference the pedagogical guidelines related to the construction of an educational project. Development: The intention is to understand how the joint is being held in the areas of health and education in the development of ongoing projects. The research happened from the analyses of eight projects and questionnaires answered by pedagogical departments. The methodological approach is qualitative using desk research and interviews in data collection. This text will dicuss the following categories: the organization of pedagogical projects in the courses, authorship and authors, and the pedagogical coordination in the processes of education. Final considerations: The results indicate work cohesion in terms of justification and objectives when it comes to educational qualification of the professionals to work at SUS. They suggest a certain weakening in some documents in comparison to the theoretical framework concerning work conceptions, more specifically in the methodological choice and evaluation process, even though the authors mentioned as theoretical partners could display support to such concepts. The projects were performed by teams, implying collaborative elaboration. The pedagogical supervision is mostly performed by professionals somehow familiarized with educational issues for having attended post-graduate courses. Few courses have pedagogues working in that position. KEYWORDS: Pedagogical project. Professional education. Unified Health System. 


\section{Introdução}

A articulação entre a área da educação e as demais áreas do conhecimento ganha destaque na elaboração do documento orientador dos cursos, o projeto pedagógico - documento que tem em sua concepção tanto questões do âmbito das definições filosóficas e pedagógicas quanto dos conhecimentos específicos de cada área. $\mathrm{Na}$ formação de profissionais da saúde, a essa demanda é somada a dimensão educativa que compõe a formação em saúde, quando o trabalho nessa área passa a ser orientado não apenas para o caráter curativo, mas assume de forma bem incisiva a necessidade de trabalhar em ações de prevenção e promoção em uma perspectiva de humanização, exigindo que conhecimentos próprios da área das ciências humanas sejam considerados na formação.

Nesta pesquisa foram investigados os projetos pedagógicos dos cursos de especialização em Saúde da Família cursados no âmbito do Programa de Valorização do Profissional da Atenção Básica (PROVAB) e Mais Médicos no Brasil, promovidos pela Rede UNA-SUS. Tais programas têm como um dos focos de investimento a formação de recursos humanos na área médica para o Sistema Único de Saúde (SUS). Dentre as ações previstas no escopo desses programas há a previsão de que todos os profissionais participarão do projeto de educação permanente oferecido pela Universidade Aberta do SUS (UNA-SUS) e pelas Universidades que compõem a Rede. Trata-se de um Curso de Especialização em Saúde da Família, na modalidade $\mathrm{EaD}$, que tem como objetivo a aproximação do ensino ao serviço e que, no momento de elaboração do projeto desta pesquisa, vinha sendo ofertado por dez das trinta e seis universidades que compõem a Rede com a UNA-SUS.

O propósito foi analisar os projetos pedagógicos dos cursos buscando compreender as estratégias utilizadas na articulação dos princípios de saúde do SUS com os princípios das Diretrizes Curriculares para a formação dos profissionais de saúde e com as orientações pedagógicas inerentes à construção de um projeto pedagógico. A finalidade, com essa triangulação, foi realizar uma análise complexa na interface das duas áreas constituidoras dessa política de formação permanente, a educação e a saúde. A intenção foi compreender de que forma está sendo realizada a articulação das áreas da saúde e da educação na elaboração de projetos de curso para a formação profissional em saúde. $O$ texto aqui apresentado trata de excerto desta pesquisa, que tem como objeto a organização e a elaboração dos projetos pedagógicos.

\section{Projeto pedagógico e a formação em saúde}

O projeto pedagógico de um curso tem a função de dar uma identidade ao trabalho. Isso significa que é a expressão escrita das razões e das intenções com determinado plano de ação. Compreende-se que o registro de um projeto é a documentação de um compromisso. Um compromisso que partiu da análise diagnóstica, da contextualização, da discussão de princípios de ação e de posicionamentos teóricos que definiram metas e caminhos para o desenvolvimento do processo educacional.

Para Veiga ${ }^{1}$, o projeto pedagógico é um documento dinâmico, construído de forma coletiva e democrática com vistas a organizar e orientar o trabalho, tanto no processo de construção como na vivência do projeto. Libâneo et al. ${ }^{2}$ (p. 345) apontam que "[...] o projeto é um documento que propõe uma direção política e pedagógica para o trabalho escolar, formula metas, prevê as ações, institui procedimentos e instrumentos de ação". Severino $^{3}$ (p. 17) refere-se à intencionalidade compartilhada e Vasconcellos ${ }^{4}$ fala da "[...] sistematização, nunca definitiva, de um processo de planejamento participativo, que se aperfeiçoa e se objetiva na caminhada".

Esses autores sustentam a força do documento como definidor da efetivação de uma proposta de ação em educação que é coletiva. As ideias e os estudos sobre projeto pedagógico são decorrentes do processo de democratização instalado no país a partir 
da Constituição de $1988^{5}$, que fortalece a autonomia como princípio e, no âmbito da educação, culmina na elaboração e promulgação da Lei de Diretrizes e Bases da Educação Nacional ${ }^{6}$.

Essa lei marca, em relação à elaboração e execução dos projetos pedagógicos, seu caráter descentralizador e aponta às instituições de ensino de todos os níveis a necessidade de participação e de exercício de autoria da comunidade escolar na definição de suas metas em relação ao processo educativo.

Com isso, emerge a discussão do lugar desse documento na vida das instituições de ensino. Aponta-se a necessidade de que sua elaboração não seja restrita meramente a uma exigência legal, a uma peça importante na avaliação institucional, mas que o documento seja "vivo" desde sua elaboração até a execução, ou a definição das estratégias que darão conta do direcionamento do trabalho para atingir os fins acordados e registrados no documento. Não é um documento para ser arquivado, mas para ser cotidianamente revisitado como forma de balizar o trabalho que vem sendo construído. Ratificando que não se trata de uma tarefa burocrática, mas pedagógica, Veiga $^{1}$ salienta a perspectiva de que o projeto pedagógico não é o agrupamento de planos de ensino e de atividades diversas. Não é para ser feito e arquivado ou encaminhado às autoridades educacionais como prova do cumprimento de tarefas burocráticas. A autora reforça a necessidade de vivenciá-lo no cotidiano do trabalho.

Assim, a elaboração de um projeto de curso é um desafio para os gestores por se constituir em um elemento definidor do trabalho a ser realizado. Trabalho esse que não está desprovido de orientações de outras instâncias, mas que exerce a sua autonomia considerando o ordenamento legal existente para a realização do curso e as demandas políticas e contextuais do grupo envolvido no processo formativo. Ou seja, quando um projeto é definido, é definido dentro de um contexto maior. Sua elaboração e execução ocorrem no âmbito das possibilidades desse contexto.

Também é importante marcar que não há um modelo único de projeto pedagógico. As instituições podem e devem marcar sua identidade no documento. Entretanto, por se tratar de um projeto, uma carta de intenções, é recomendável que se pense e que se registre a situação inicial e aonde se quer chegar. Também há a necessidade de registrar as estratégias que serão utilizadas para o alcance dos objetivos propostos, como serão organizadas as ações e que metodologia será desenvolvida. Utilizando outras denominações, Danilo Gandin ${ }^{7}$ e Celso Vasconcellos ${ }^{4}$ destacam três etapas constituintes do projeto político pedagógico: o Marco Referencial, composto pelo Marco Situacional, o Marco Político-Filosófico e o Marco Operativo; a constituição de um Diagnóstico; e o estabelecimento da Programação. Para os autores, essas etapas conduzem à reflexão dentro do processo de elaboração do projeto - de forma que seus autores assumam as referências analisando onde estão, o que querem alcançar e de que forma planejam isso.

Confirmando o que dizem os autores, aponto que as definições ou interpretações sobre esses marcos estão necessariamente sustentadas por formas de compreender o processo educativo e, nesse sentido, o projeto precisa expressar as concepções epistemológicas que sustentam seu desenvolvimento, as bases teóricas que fundamentam a compreensão sobre o processo de ensino e de aprendizagem, bem como os seus desdobramentos em metodologias e práticas docentes que possam levar à efetivação de um projeto educacional ${ }^{8}$. São dimensões do documento que contemplam a qualidade formal do registro com os posicionamentos teórico-metodológicos e a qualidade política, tanto de elaboração quanto de planejamento de ações com os posicionamentos políticos.

Assim, os projetos de curso falam de si e de seus contextos. Posicionam-se teoricamente para sustentar suas estratégias metodológicas, criam e gerenciam processos buscando a efetivação de seus objetivos que, nesse caso em estudo, não são singulares, já que os programas se inscrevem no contexto de políticas formativas bem definidas em saúde, que têm como objetivo potencializar as ações do SUS e 
qualificar o trabalho dos profissionais da saúde na perspectiva da atenção integral. No que tange a esta pesquisa, os projetos dos cursos de especialização precisam estar organizados seguindo as orientações da UNA-SUS, que tem como determinantes os princípios do SUS para o desenvolvimento do trabalho. Além disso, devem seguir as determinações legais em relação à educação a distância no país.

A rede UNA-SUS vem construindo um projeto de formação de profissionais da saúde aliado à possibilidade de acesso às inovações que se colocam no âmbito das tecnologias digitais aplicadas à educação. Como dizem Garrido e Schlemmer ${ }^{8}$ (p. 1):

Qualquer que seja a modalidade de educação, sendo ela a distância ou não, precisa considerar aspectos de relevância para promoção de uma formação de qualidade, que tem início com um Projeto Político-Pedagógico - PPP claro e bem delineado.

Mas precisamos compreender que o planejamento do processo de ensino e aprendizagem a distância tem singularidades e possibilidades de ação próprias desta modalidade. A modalidade educativa em EaD vai além do simples oferecimento de informações por meio de um ambiente virtual de aprendizagem (AVA). É preciso que os alunos tenham condições de acesso à informação, um cuidadoso preparo na forma de trabalho dos conhecimentos e estratégias metodológicas que viabilizem as interações cabíveis à construção do aprendizado. Todas essas definições e ações ocorrem em um contexto epistemológico e político. Assim, a definição de caminhos nos projetos em EaD são posicionamentos necessários que marcam a intencionalidade do trabalho e justificam escolhas na administração do processo de trabalho.

\section{Metodologia da pesquisa}

Esta pesquisa foi realizada em uma perspectiva de trabalho qualitativa porque pretendeu analisar a experiência do registro de projetos de educação, dando ênfase à interpretação e à compreensão no tratamento dos dados e das informações. Essa abordagem é "[...] a presença ou a ausência de uma dada característica de conteúdo ou de um conjunto de características num determinado fragmento de mensagem que é tomado em consideração"9 (p. 21). Busca uma aproximação com os contextos de significação em que foram produzidos os documentos e nele estão inscritos. Santos e Sánchez $\operatorname{Gamboa}^{10}$ (p. 27), ao abordar a contribuição de Dilthey à pesquisa em ciências humanas, diz que "[...] compreender é conhecer o que alguém está experienciando por meio de uma recriação daquela experiência, ou do contexto daquela experiência em si mesma".

A intenção foi compreender como foram construídos os projetos pedagógicos na área da saúde, tendo como foco os cursos de especialização em Saúde da Família (UNA-SUS). Participaram oito das dez instituições de ensino superior que compunham a Rede UNA-SUS quando da organização deste projeto de pesquisa. Todas assinaram o Termo de Consentimento Livre e Esclarecido, aprovado junto ao projeto de pesquisa sob o $\mathrm{n}^{\circ}$ CEP 15/101. A análise do conteúdo realizada a partir do recolhimento dos documentos foi norteada pelos procedimentos metodológicos teorizados por Bardin ${ }^{9}$ (p. 31), mas tendo presente o que ela própria marca na produção de um processo de investigação em ciências sociais:

Não existe o pronto-a-vestir em análise de conteúdo, mas somente algumas regras de base, por vezes, dificilmente transponíveis. A técnica de análise de conteúdo adequada ao domínio e ao objetivo pretendidos tem que ser reinventada a cada momento, exceto para usos simples e generalizados, como é o caso do escrutínio próximo da decodificação e de respostas a perguntas abertas de questionários cujo conteúdo é avaliado rapidamente por temas.

Inspirada nessa ideia de adequação ao que está sendo investigado e buscando manter a vigilância epistemológica sobre os processos da pesquisa, os procedimentos foram se organizando sustentados pelos objetivos a que a pesquisa se propôs chegar. 
Inicialmente foi realizada uma leitura flutuante para aproximação com o material em análise, buscando uma intenção heurística com os dados. Essa fase exploratória permitiu reconhecer alguns índices nos textos que convergiam para os propósitos desta pesquisa, como também buscou aspectos significativos presentes nos projetos pedagógicos.

Essa etapa suscitou questionamentos que não estavam explicitados nos projetos e que foram direcionados às coordenações pedagógicas dos cursos, utilizando como instrumento um questionário aberto realizado a distância, por e-mail, buscando viabilizar a aproximação com as propostas. Gonçalo e Barros ${ }^{11}$ (p. 636), em artigo de revisão sistemática da literatura referente ao uso de entrevistas realizadas a distância, afirmam que:

[...] a literatura revela que a incorporação do uso de entrevistas via telefone e e-mail na pesquisa qualitativa em saúde é um fato pertinente (MANN; STEWART, 2000; ASELTON, 2012), principalmente porque vários autores identificaram que as entrevistas realizadas a distância (ED) têm apresentado características relevantes, tais como a redução do tempo de entrevista, o favorecimento de maior taxa de resposta (EVANS et al., 2004; PINTO-MEZA et al., 2005; FEVEILLE; OLSEN; HOGH, 2007; ROCHELEAU et al., 2012) e a redução de custos (LANG et al., 2011; JOHANSEN; WEDDERKOPP, 2010; NAGELHOUT et al., 2010; WARDKING et al., 2010).

O questionário foi respondido por seis das oito coordenações de curso. O conjunto dos dados produzidos a partir da análise dos projetos pedagógicos e dos questionários deu origem às categorias de análise. Este texto abordará as seguintes: a organização dos projetos pedagógicos dos cursos; autorias e autores; e a coordenação pedagógica nos processos de formação.

\section{Sinteses construidas}

\section{A organização dos projetos pedagógicos dos cursos}

Os projetos pedagógicos são documentos decorrentes de uma necessidade, construída historicamente de posicionamento das escolas em relação às suas concepções teórico-metodológicas em um contexto em que as identidades têm espaço de existência, que já não cabem mais modelos prescritivos e homogeneizantes de administração dessas instituições. Nesse sentido, o Regimento que até então organizava o cotidiano das escolas já não abarca mais toda a complexidade, em termos pedagógicos, de posicionamento teórico e de proposição de ações. O projeto pedagógico tem, nesse contexto, objetivo de marcar a intencionalidade das instituições de ensino de forma contextualizada a partir de leituras de realidade.

Como já mencionado, não há uma única forma de organizar esse documento. No entanto, em função dos atributos próprios da sua criação, parece importante que alguns aspectos sejam considerados. Com que justificativa surgem, que perspectivas teórico-metodológicas sustentam suas ações e como estão organizadas essas ações para a transformação da realidade?

Em relação à justificativa - o lugar onde geralmente se apresenta uma leitura da realidade e se constroem argumentos para explicar a relevância da proposta de curso - fica evidenciado que há a consolidação de um argumento coletivo, que envolve projetos de diferentes universidades na condução de processos formativos em saúde. Fica demonstrado que a efetivação desses projetos na modalidade EaD possibilita o acesso a profissionais que trabalham em regiões distanciadas dos grandes centros urbanos, atingindo todos os Estados e o Distrito Federal, e cria condições para que a articulação ensino-serviço ocorra nos seus contextos de atuação. As justificativas, coerentes a um projeto maior de formação coordenado pela rede UNA-SUS, potencializam e concretizam, em termos de registro nos projetos, a intenção de " [...] 
pactuar com a gestão do SUS para garantir objetivos educacionais e público-alvo adequados às necessidades de saúde do Brasil"12.

Esse posicionamento realizado nos projetos constitui parte do que Vasconcellos ${ }^{4}$ compreende como Marco Referencial. Neste espaço de registro de um projeto, nos situamos na realidade a partir de sua leitura (marco situacional) e tomamos posição em relação a opções político-pedagógicas (marco filosófico e operativo). As justificativas, nessa perspectiva de elaboração de projetos de curso, trazem de forma plena o marco situacional quando contextualizam o projeto de formação e, de certa maneira, avançam no marco filosófico e operativo ao posicionarem-se na perspectiva de trabalho com metodologias ativas.

Há bem caracterizada a intenção de inovar, em termos metodológicos, com a utilização de metodologias ativas. Entretanto, há poucos casos em que o projeto apresenta posicionamentos pedagógicos anteriores à escolha metodológica. Dos oito projetos analisados, três não fazem referência às concepções de ensinar e aprender. Outros três projetos apresentam timidamente tal questão e de forma diluída no documento. Apenas dois projetos apresentam essas concepções de forma clara e, a partir dessa disposição, fazem uma escolha metodológica.

Ao abordar a questão da inovação nas práticas pedagógicas, Cunha et al. ${ }^{13}$, apoiados em pesquisas realizadas sobre formação de professores ${ }^{14-16}$, nos alerta que é muito marcante na forma de ensinar dos professores as suas experiências como alunos. A autora afirma que inovação em educação não se limita à agregação de novos elementos tecnológicos, mas a possibilidade de romper com formas institucionalizadas de ensino. Inovar como a possibilidade de pensar novas formas de ensinar e aprender. Nesse sentido, potencializar a ação docente nos cursos, na perspectiva da inovação metodológica, passa por pensar nos elementos fundantes do trabalho: o ensinar e o aprender.

Sobral e Campos $^{17}$ (p. 215), em pesquisa de revisão integrativa sobre o uso de metodologias ativas no curso de enfermagem no Brasil, destacam que, em alguns artigos,

[...] não havia muitas informações sobre a aplicação das metodologias adotadas e nem do referencial teórico; é possível que o uso dessas práticas pedagógicas tenha ocorrido empiricamente, apresentando pouca fundamentação teórica.

Os autores chamam a atenção em seus achados para o fato de que a falta de referenciais teóricos para planejar a ação pedagógica pode contribuir para uma mudança superficial, de alteração de técnicas, o que nem sempre caracteriza a inovação do método.

O cuidado com o arcabouço teórico que sustenta as práticas pedagógicas é importante por ele se constituir em uma diretriz de análise da prática. Em que medida o que vem sendo proposto e realizado no âmbito de um curso está ancorado nos aportes teóricos assumidos no projeto? É uma instância de produção científica, na medida em que baliza o trabalho desenvolvido. Veiga ${ }^{18}$ (p. 14) comenta que "[...] a questão é, pois, saber a qual referencial temos que recorrer para a compreensão de nossa prática pedagógica. Nesse sentido, temos que nos alicerçar nos pressupostos de uma teoria pedagógica [...]".

A ausência desse arcabouço no documento não significa necessariamente que a condução do processo de ensino e de aprendizagem esteja desconectada dos princípios das metodologias ativas, assumidas de forma coesa pelos projetos, mas em certo sentido pode fragilizar a sustentação, tanto das argumentações sobre o processo formativo quanto das ações advindas dele.

No âmbito dos projetos, a repercussão dessa ausência se dá na sustentação teórica das metodologias ativas e, em alguns casos, na sustentação do processo avaliativo dos alunos. Isso é percebido porque em quatro projetos a avaliação é descrita em sua forma, ou operacionalização (instrumentos, frequência, peso das avaliações, 
que são presenciais...). Nesses projetos não há menção às concepções subjacentes ao processo. Na esteira da argumentação utilizada em relação ao apoio teórico para a sustentação do uso de metodologias ativas, o processo de avaliação também fica pouco amparado. As concepções de aprendizagem estão muito vinculadas à forma de organizar a avaliação. Os instrumentos utilizados, a forma de elaboração, a maneira como os resultados serão utilizados no processo ensino e aprendizagem são alguns aspectos que se colocam como repercussão das concepções assumidas. E não é incomum encontrarmos trabalhos docentes com estratégias metodológicas diferenciadas, mas que permanecem com processos avaliativos classificatórios e pouco voltados para a formação dos alunos. Nesse sentido, posicionar-se teoricamente em relação à avaliação parece ser um constructo importante de ser levado em conta na elaboração de projetos de curso.

\section{Autorias e autores}

Esta categoria de análise traz dados relativos às autorias dos documentos, ou seja, quem participou na elaboração dos projetos pedagógicos. Também apresenta quais autores são referidos pelas coordenações pedagógicas como parceiros teóricos na elaboração dos projetos, no que tange aos aspectos pedagógicos dos documentos. Justifico a aproximação de ambos os dados (autorias e autores), que podem à primeira vista parecerem desconectados, por considerar que são formas de participação de um mesmo processo, com inserções em perspectivas diferenciadas, mas que produzem efeitos importantes no constructo final.

Um aspecto caro aos estudiosos do tema projeto pedagógico diz respeito ao processo de sua elaboração. Justamente por ser um documento que aponta na perspectiva da democratização das instituições de ensino e dos processos educacionais, a dimensão política da participação tem um acento importante no processo de construção do projeto. A LDB 9394/96, em seu artigo 13, refere a participação dos profissionais da educação na elaboração do projeto pedagógico com vistas a um processo de gestão democrática na educação ${ }^{6}$. Nesse sentido, $\operatorname{Vasconcellos}^{4}$ (p. 25) comenta, reiterando as palavras de Paulo Freire, que "[...] o projeto deve expressar de maneira simples (o que não significa dizer simplista) as opções, os compromissos, a visão de mundo e as tarefas assumidas pelo grupo [...]". Os compromissos farão parte da agenda dos sujeitos envolvidos com o processo formativo na mesma medida em que eles se sentirem, e de fato forem, autores do documento. Nesse sentido, Benavente ${ }^{19}$ (p. 28) comenta que "[...] as inovações não têm hipóteses de sucesso se os atores não são chamados a aceitar essas inovações e não se envolvem na sua própria construção".

Nos questionários realizados, as coordenações pedagógicas mencionaram, de forma unânime, que os cursos de especialização analisados nesta pesquisa foram construídos por equipes buscando envolver diferentes atores para, dessa forma, ampliar o diálogo. Assim, há menção à participação de docentes na construção de três PPCs; outros três referem que o documento foi elaborado por uma comissão; e há um caso em que participaram integrantes da Secretaria Estadual de Saúde e da Associação de Médicos.

Articulado a essa discussão de suporte teórico nos projetos, por meio do questionário realizado com as coordenações pedagógicas, foi perguntado sobre os autores que embasaram a elaboração do documento. O autor mais citado como referência foi Paulo Freire, por cinco coordenadoras. Jean Piaget foi citado duas vezes e os demais, apenas uma vez: Antoni Zabala, Cesar Coll, Cipriano Luckesi, Fernando Becker, Hannah Arendt, Jean Piaget, Juan Bordenave, Lev Vygotsky, Maria Cristina Davini, Maria Montessori, Martin Heidegger e Philippe Perrenoud. Retornando à argumentação que defende a aproximação das autorias aos autores, parece interessante constatar que os autores mencionados como suporte teórico, de maneira geral, mesmo que não sejam pesquisadores diretamente vinculados à temática de projetos pedagógicos, desenvolvem trabalhos em perspectivas teóricas convergentes aos princípios 
preconizados à elaboração coletiva do trabalho em educação. Estudiosos do processo de aprendizagem, de maneira geral, são os suportes teóricos mais utilizados.

Cabe retomar as reflexões trazidas na categoria anterior, que discutiu sobre a pouca explicitação nos projetos pedagógicos das concepções de ensinar e aprender. No entanto, de forma paradoxal, no que diz respeito aos autores utilizados, são os teóricos que discutem tais concepções os prevalentes nas respostas das coordenações pedagógicas. Bordenave ${ }^{20}$ nos ajuda a pensar que:

Todos os processos educativos, assim como suas respectivas metodologias e meios, têm por base uma determinada pedagogia, isto é, uma concepção de como se consegue que as pessoas aprendam alguma coisa e, a partir daí, modifiquem seu comportamento. A pedagogia escolhida, por sua vez, se fundamenta em uma determinada epistemologia ou teoria do conhecimento. As opções pedagógicas adotadas por um determinado contexto refletem as ideologias (e os objetivos) desse referido contexto.

O autor chama a atenção para o fato de que há sempre uma pedagogia por traz de uma prática. Uma fundamentação, ainda que não referida, ao que está sendo proposto, que reflete as concepções assumidas e que balizará o processo de formação tendo o PPC como referência. Isto não significa cerceamento, mas planejamento e intencionalidade nas ações, de forma propositiva e assumida em um projeto que poderá sofrer alterações, caso se façam necessárias.

\section{A coordenação pedagógica nos processos de formação}

Apresento aqui a reflexão sobre quem exerce a função de coordenação pedagógica nos cursos de pós-graduação analisados. É importante considerar nesta discussão, que atinge importância pela centralidade da dimensão da educação na formação dos profissionais da saúde na contemporaneidade, a formação das coordenações pedagógicas dos cursos analisados. Este aspecto foi explorado nos questionários, tendo em vista que não foi possível ter essa informação em todos os PPCs.

Os dados indicam que há preocupação com a vinculação à função de coordenação pedagógica de profissionais com alguma formação na área da educação. Três cursos contam com pedagogas realizando esse trabalho, outros três cursos têm profissionais sem a formação em pedagogia em nível de graduação, mas possuem cursos de pós-graduação vinculados à área, quais sejam: cursos latu sensu: especialização em docência, especialização em EaD, especialização em processos educacionais em saúde, especialização em gestão pedagógica para escolas técnicas do SUS; curso stricto sensu: mestrado em educação. Apenas um questionário mencionou que a coordenação pedagógica é realizada por profissional sem formação em educação.

A legislação brasileira orienta sobre a formação dos profissionais que atuam nesses cargos, mas direciona o ordenamento para a Educação Básica. A LDB 9394/96, no artigo 64, diz que a formação de profissionais de educação para a administração, planejamento, inspeção, supervisão e orientação educacional para a educação básica será feita em cursos de graduação em pedagogia ou em nível de pós-graduação, a critério da instituição de ensino ${ }^{6}$.

Talvez seja interessante refletir sobre esse trabalho no processo formativo e de desenvolvimento de um projeto pedagógico. O profissional que desempenha a função de coordenação pedagógica tem como principal atribuição a assistência didático-pedagógica, refletindo sobre as práticas de ensino, auxiliando e construindo novas situações de aprendizagem capazes de auxiliar o processo de formação. Autores dessa área contribuem com ideias. Freire ${ }^{21}$ defende que o coordenador pedagógico é, primeiramente, um educador e, como tal, deve estar atento ao caráter pedagógico das relações de aprendizagem. Gandinn ${ }^{22}$ chama a atenção para o fato de este profissional ser responsável em executar um esquema de trabalho que dê conta do planejamento e das mediações necessárias no processo educativo. Libâneo ${ }^{23}$ comenta que o coordenador supervisiona, acompanha, assessora, apoia e avalia as 
atividades pedagógicas curriculares, e sua atribuição prioritária é prestar assistência pedagógico-didática aos professores em suas respectivas disciplinas.

Percebe-se que a demanda de trabalho vem aproximando profissionais da saúde da área da educação e isso é fundamental para a efetivação da proposta do SUS. Da mesma forma, os dados apontam para a aproximação de profissionais da área da educação à área da saúde, contribuindo com conhecimentos próprios da sua formação e ajudando a pensar a articulação de áreas fundamentais no projeto de formação de profissionais da saúde. Reitera-se, entretanto, que coordenar a condução de um projeto pedagógico é primordial para o alcance dos objetivos propostos e marca a intencionalidade do trabalho, que não começa em si mesmo mas que está em consonância a outras orientações que vislumbram a transformação em nível macro na formação de profissionais da saúde. Como decorrência, na assistência aos usuários.

\section{Considerações finais}

O projeto pedagógico é um instrumento balizador das ações em um processo de ensino e aprendizagem. Este trabalho apresentou análises realizadas a partir dos registros desses documentos na área da saúde, mais especificamente no âmbito dos Cursos de Especialização em Saúde da Família oferecidos pela rede UNA-SUS.

As análises demostraram um trabalho bem orquestrado no que tange à coordenação da UNA-SUS, potencializando o objetivo a que este sistema se coloca de qualificação da formação dos profissionais da saúde no país com foco no atendimento no SUS.

Os projetos indicam de forma coesa a intenção de utilização de metodologias ativas na formação dos profissionais. No entanto, essa escolha nem sempre vem sustentada pela explicitação de concepções importantes no processo de formação, como o que concebe ensinar e aprender. A ausência de concepções também é percebida nas seções dos documentos que tratam do processo de avaliação, onde alguns projetos não deixam claro de que forma está sendo compreendida a avaliação no processo formativo. Paradoxalmente os autores citados como parceiros teóricos na elaboração dos documentos são, principalmente, autores que discutem o processo de aprendizagem.

Em relação às autorias dos documentos, a manifestação prevalente é de que foram elaborados por equipes envolvendo diferentes profissionais e de diferentes áreas. Isto indica que a necessidade de construção coletiva desse documento, que surge justamente com a intenção de democratizar os processos nas instituições de ensino, garantindo que o próprio processo de construção já se constituísse em formação para seus participantes, se apresenta no escopo desta pesquisa como realidade.

As coordenações pedagógicas são realizadas majoritariamente por profissionais com alguma aproximação às questões da educação pela realização de cursos de pós-graduação. Poucos cursos, entretanto, têm pedagogas desempenhando tal função. Talvez esse seja um dos motivos de concepções importantes na sustentação teórica de tais cursos não serem explicitados nos documentos. Tal dado parece indicar a necessidade de investimento nessa aproximação de forma mais efetiva.

A construção de projetos pedagógicos para cursos de formação profissional na área da saúde tem se colocado como um desafio no ensino na saúde. Alguns movimentos importantes, como a experiência apresentada aqui, já são percebidos, indicando que a aproximação dessas áreas é qualificadora de ambas e, especialmente, do atendimento em saúde que pretenda um trabalho mais humanizado, conforme orienta o SUS.

\section{Referências}

1. Veiga IPA. Inovações e projeto político-pedagógico: uma relação regulatória ou emancipatória? Cad Cedes. 2003;23(61):26781. http://dx.doi.org/10.1590/S0101-32622003006100002. 
2. Libâneo JC, Oliveira JF, Toschi M. Educação escolar: políticas, estrutura e organização. 7. ed. São Paulo: Cortez; 2009.

3. Severino AJ. O diretor e o cotidiano da escola. In: Ideias. São Paulo: FDE; 1992.

4. Vasconcellos CS. Coordenação do trabalho pedagógico: do projeto político-pedagógico ao cotidiano da sala de aula. São Paulo: Libertad; 2002.

5. Brasil. Constituição da República Federativa do Brasil: 1988. Porto Alegre: Edição da Assembléia Legislativa do Estado do Rio Grande do Sul; 1991.

6. Brasil. Lei de Diretrizes e Bases da Educação Nacional. LDB no 9394/1996 [citado em 2016 Maio 17]. Disponível em: http://www.planalto.gov.br/ccivil_03/leis/L9394.htm

7. Gandin D. Planejamento como prática educativa. São Paulo: Edições Loyola; 1998.

8. Garrido SL, Schlemmer E. Reflexões sobre o Projeto Político-Pedagógico para Educação a Distância (on line). TC. 2006;3:C1-073.

9. Bardin, L. Análise de conteúdo. Lisboa: Edições 70; 1977.

10. Santos JC Fo, Sánchez Gamboa S. Pesquisa Educacional: quantidade-qualidade. 6. ed. São Paulo: Cortez; 2007. Coleção Questões de Nossa Época, 42.

11. Gonçalo CS, Barros NF. Entrevistas realizadas a distância no campo da pesquisa qualitativa em saúde. Cad Ter Ocup UFSCar. 2013;21(3):635-44.

12. Universidade Aberta do SUS - UNA-SUS. Profissionais de saúde [Internet]. 2016 [citado em 2016 Maio 17]. Disponível em: http://unasus.gov.br/page/o-que-fazemos/como-podemos-ajudar/trabalhadores-do-sus

13. Cunha MI, Marsico HL, Borges FA, Tavares P. Inovações pedagógicas na formação inicial de professores. In: Barboza Fernandes CM, Grillo M. Educação Superior: travessias e atravessamentos. Canoas: ULBRA; 2001.

14. Cunha MI. O professor universitário na transição de paradigmas. Araraquara: JM Editora; 1998.

15. Pimentel MG. O professor em construção. Campinas: Papirus; 1993.

16. André M. O papel da pesquisa na articulação entre saber e pratica docente. ln: Anais do $7^{\circ}$ Encontro Nacional de Didática e Prática de Ensino; 1994; Goiânia. Goiânia: S.R.P.; 1994. p. 291-6.

17. Sobral FR, Campos CJG. Utilização de metodologia ativa no ensino e assistência de enfermagem na produção nacional: revisão integrativa. Rev Esc Enferm USP. 2012;46(1):208-18. PMid:22441286. http://dx.doi.org/10.1590/S0080-62342012000100028.

18. Veiga IPA. Projeto político-pedagógico da escola: uma construção possível. Campinas: Papirus; 1995.

19. Benavente A. As ciências da educação e a inovação das práticas educativas. In: Sociedade Portuguesa de Ciencias da Educação. Decisões nas políticas e práticas educativas. Porto: SPCE; 1992.

20. Bordenave JED. Alguns fatores pedagógicos. In: Grandi MT. Brasília: OPAS; 1983. Texto traduzido e adaptado do artigo ‘La Transferencia de Tecnología Apropiada al Pequeño Agricultor (Bordenave, J E D. Revista Interamericana de Educação de Adultos, v. 3, n. 1-2 - PRDE-OEA) para a Capacitação Pedagógica do Programa de Formação de Pessoal de Nível Médio em Saúde. Projeto Larga Escala.

21. Freire P. Educação: sonho possível. In: Brandão CR, editor. O educador: vida e morte. 2. ed. Rio de Janeiro: Graal; 1982.

22. Gandin D. Planejamento como prática educativa. 14. ed. São Paulo: Loyola; 2004.

23. Libâneo JC. Organização e de gestão da escola: teoria e prática. Goiânia: Alternativa; 2001.

\section{Contribuição dos autores}

A autora realizou a pesquisa e produziu o artigo em sua integralidade. 